\title{
Azithromycin Prevents Pregnancy Loss: Reducing the Level of Tumor Necrosis Factor-Alpha and Raising the Level of Interleukin-10 in Rats
}

\begin{abstract}
Ayse Er
Department of Pharmacology and Toxicology, Faculty of Veterinary Medicine, University of Selcuk, 42075 Konya, Turkey

Correspondence should be addressed to Ayse Er; aer@selcuk.edu.tr

Received 21 August 2013; Revised 11 October 2013; Accepted 31 October 2013

Academic Editor: Dariusz J. Skarzyński

Copyright (C) 2013 Ayse Er. This is an open access article distributed under the Creative Commons Attribution License, which permits unrestricted use, distribution, and reproduction in any medium, provided the original work is properly cited.

The aim of this study was to determine the effect of azithromycin on LPS-induced pregnancy loss. Thirty-six pregnant female Wistar rats were divided into 4 equal groups as follows: control group, where $0.3 \mathrm{~mL}$ of normal saline solution was administered intravenously on day 10 of pregnancy; azithromycin group, where azithromycin was administered orally at $350 \mathrm{mg} \mathrm{kg}^{-1}$ day on days 9, 10, and 11 of pregnancy; lipopolysaccharide group, where LPS was administered intravenously via the tail vein at $160 \mu \mathrm{gg}^{-1}$ on day 10 of pregnancy; and the azithromycin + LPS group, where azithromycin was administered orally at $350 \mathrm{mg} \mathrm{kg}^{-1}$ day on days 9,10 , and 11 of pregnancy and LPS was administered intravenously at $160 \mu \mathrm{g} \mathrm{kg}^{-1}$ on day 10 of pregnancy. Blood samples were obtained from the tail vein on day 10 of the experiment. Pregnancy rates were determined. Tumor necrosis factor-alpha (TNF- $\alpha$ ) and interleukin (IL-10) levels were measured by ELISA. Azithromycin prevented $(P<0.05)$ LPS-induced pregnancy loss. Higher TNF$\alpha$ and IL-10 levels were measured $(P<0.05)$ in the LPS and azithromycin + LPS groups, respectively. In conclusion, azithromycin may be useful in infection- or endotoxemia-dependent pregnancy loss.
\end{abstract}

\section{Introduction}

The maternal immune system is capable of recognizing and refusing a response against foetal antigens [1]. One of the most common unfavorable outcomes during the first trimester of pregnancy is spontaneous abortion; the rate of spontaneous abortion is $15 \%-20 \%$ in women [2]. However, the mechanisms underlying pregnancy loss caused by maternal infections are not clear [3].

Lipopolysaccharide (LPS), an endotoxin derived from gram negative bacteria, has been used to constitute inflammatory response in experimental studies with pregnancy. It is well known as a trigger of abortion and preterm birth via proinflammatory cytokines and nitric oxide [4-9]. The predominant production of T-helper (Th2) cytokines is a characteristic of normal pregnancy, while a predominant production of Thl cytokines is a characteristic of abortion and recurrent abortion [10]. A change from a Th2-biased to a Th1-biased cytokine profile in maternal serum results in complications for pregnant women, such as spontaneous abortions and preeclampsia [11].
Besides the direct antimicrobial effect, macrolides also show anti-inflammatory properties [12]. Azithromycin has similar efficacy compared with erythromycin or amoxicillin; azithromycin also has fewer adverse effects in the treatment of pregnant women with Chlamydia trachomatis infections [13]. Because of this feature, using azithromycin to treat pregnant women with uncomplicated C. trachomatis infections is increasing amongst obstetricians [14]. Azithromycin is clinically effective in the treatment of common respiratory, skin/skin-structure infections, nongonococcal urethritis, and cervicitis due to $C$. trachomatis. Azithromycin is categorized as a class B drug during pregnancy [15].

The balance between tumor necrosis factor-alpha (TNF$\alpha$ ) and interleukin (IL-10) is determined for pregnancy success. Whenever the level of TNF- $\alpha$ increases, abortion occurs, while IL-10 supports the pregnancy $[10,11]$. Due to the inexistence of an adequate preventive treatment of early pregnancy loss, it has been hypothesized that azithromycin may prevent LPS-induced pregnancy loss because of an inhibitory effect on TNF- $\alpha$ and potentiating effect on IL-10. 
The aim of this study was to determine the effect of azithromycin on LPS-induced pregnancy loss in rats.

\section{Materials and Methods}

2.1. Animal. The study protocol was approved by the Ethical Committee of Necmettin Erbakan University, Experimental Medicine, Research and Application Center, Konya, Turkey. Thirty-six female and 9 male Wistar rats $(272 \pm 44.9 \mathrm{~g}$ and $306 \pm 16.1$ g, respectively, 5-6 months old) were used in this study. Rats were fed a standard pelleted diet and tap water was provided ad libitum as drinking water. Animals were bred in standard cages on a $12 \mathrm{hr}$ light/dark cycle at room temperature in a humidity-controlled environment.

2.2. Experimental Procedure. LPS (Escherichia coli, serotype O111:B4, Sigma-Aldrich Chemie, Deisenhofen, Germany) and azithromycin (Zitromax, $200 \mathrm{mg} / 5 \mathrm{~mL}$, oral suspension, Pfizer, Istanbul, Turkey) were diluted with pyrogen-free saline to appropriate concentrations.

Female rats were caged with males for 1 day and the presence of a vaginal plug was designated as day 0 of pregnancy. Tenth to 12th day in a rat's pregnancy corresponds roughly to the first trimester of human pregnancy [16]. Pregnant rats were randomly divided into 4 groups as follows: control group, where $0.3 \mathrm{~mL}$ of normal saline solution was administered intravenously on day 10 of pregnancy $(n=9)$; azithromycin group, where azithromycin was administered orally at $350 \mathrm{mg} \mathrm{kg}^{-1}$ day on days 9, 10, and 11 of pregnancy ( $n=9$ ); where LPS group, LPS was administered intravenously via the tail vein at $160 \mathrm{\mu g} \mathrm{kg}^{-1}$ on day $10 \mathrm{of}$ pregnancy $(n=9)$; and the azithromycin + LPS group, where azithromycin was administered orally at $350 \mathrm{mg} \mathrm{kg}^{-1}$ day on days 9,10 , and 11 of pregnancy and LPS was administered intravenously at $160 \mu \mathrm{g} \mathrm{kg}^{-1}$ on day 10 of pregnancy $(n=$ 9). Blood samples were obtained from the tail vein on day 10 of the experiment ( $3 \mathrm{hr}$ after LPS administration) and all animals were followed during pregnancy. In addition, animals that did and did not give birth were determined. At the end of the study, all animals were euthanized under thiopental sodium anaesthesia $(70 \mathrm{mg} / \mathrm{kg}$, intraperitoneally; Pental Sodium $1 \mathrm{~g}$ inj., I. E. Ulagay Ilac Sanayi, Istanbul, Turkey).

2.3. Measurements. Samples were centrifuged and serum samples were stored at $-70^{\circ} \mathrm{C}$ until analysis. TNF- $\alpha$ (eBioscience Rat TNF- $\alpha$ kit, sensitivity $11 \mathrm{pg} / \mathrm{mL}$, San Diego, CA, USA) and IL-10 (eBioscience Rat IL-10kit, sensitivity $1.5 \mathrm{pg} / \mathrm{mL}$, San Diego, CA, USA) levels were determined at $450 \mathrm{~nm}$ by commercial ELISA kits with ELISA reader (MWGt Lambda Scan 200, USA).

2.4. Statistical Analysis. The pregnancy rates of the groups were evaluated using a chi-square test, and the concentrations of TNF- $\alpha$ and IL-10 were compared with ANOVA and the Tukey test. Data are expressed as the mean \pm SE. Number of offspring in each group was evaluated by ANOVA and Duncan test. Significance was accepted at the $P<0.05$ level.
TABle 1: Pregnancy rates of groups.

\begin{tabular}{lcc}
\hline Drug & Pregnant/pregnancy loss & Labour animals \\
\hline Control & $9 / 0^{\mathrm{a}}$ & 9 \\
Azithromycin & $9 / 0^{\mathrm{a}}$ & 9 \\
LPS & $9 / 7^{\mathrm{b}}$ & 2 \\
Azithromycin + LPS & $9 / 2^{\mathrm{a}}$ & 7 \\
\hline
\end{tabular}

LPS: lipopolysaccharide $\left(160 \mu \mathrm{g} \mathrm{kg}^{-1}\right.$ intravenously, Escherichia coli 0111:B4). ${ }^{\mathrm{a}, \mathrm{b}}$ Different letters in the same column are statistically significant $(P<0.05)$.

TABLE 2: TNF $\alpha$ and IL-10 levels of groups.

\begin{tabular}{lcc}
\hline & TNF $\alpha(\mathrm{pg} / \mathrm{mL})$ & IL-10 $(\mathrm{pg} / \mathrm{mL})$ \\
\hline Control & $\mathrm{ND}$ & $90.2 \pm 4.31^{\mathrm{a}}$ \\
Azithromycin & $58.2 \pm 9.56^{\mathrm{a}}$ & $113 \pm 15.4^{\mathrm{a}}$ \\
LPS & $128 \pm 10.7^{\mathrm{b}}$ & $496 \pm 149^{\mathrm{b}}$ \\
Azithromycin + LPS & $96.6 \pm 10.2^{\mathrm{c}}$ & $1130 \pm 87.4^{\mathrm{c}}$ \\
\hline
\end{tabular}

TNF $\alpha$ : tumor necrosis factor $\alpha$; IL-10: interleukin-10; LPS: lipopolysaccharide $\left(160 \mu \mathrm{g} \mathrm{kg}^{-1}\right.$ intravenously, Escherichia coli 0111:B4). ND: not determined. ${ }^{\mathrm{a}, \mathrm{b}, \mathrm{c}}$ Different letters in the same column are statistically significant $(P<0.05)$.

\section{Results}

All animals were followed during pregnancy. The average weight of the rats was $272 \pm 44.9 \mathrm{~g}$ before pregnancy and $375 \pm 47.9 \mathrm{~g}$ at the end of pregnancy. Azithromycin inhibited $(P<0.05)$ LPS-induced pregnancy loss, and there were no adverse effects on the pregnancy rate (Table 1 ). The TNF- $\alpha$ level was higher $(P<0.05)$ in the LPS group, and the IL10 levels were lower $(P<0.05)$ in the azithromycin and control groups (Table 2). In addition, the concentration of IL10 in the azithromycin + LPS group was significantly higher $(P<0.05)$ than the other groups (Table 2$)$. Offspring rate was statistically significant $(P<0.05)$ in LPS group when compared to all other groups (Figure 1).

\section{Comment}

The aim of this study was to determine the effect of azithromycin on septic abortion. Many endogenous agents, such as prostaglandins or cytokines, play a pivotal role during pregnancy $[10,17]$. Recurrent spontaneous abortion is classically defined as three or more pregnancy losses and usually occurs before 20 weeks of gestation. Recently, recurrent spontaneous abortion has been redefined as the spontaneous loss of two or more clinical pregnancies [18, 19]. Adverse pregnancy outcomes, such as spontaneous abortion, preterm labour, preeclampsia, and intrauterine growth restriction, can result from a deregulation of cytokines networks [20].

In the current study, azithromycin alone did not present a negative effect on the pregnancy rate (Table 1). It has been reported that the prophylactic use of azithromycin can decrease procedure-related pregnancy loss and may be safe in pregnant women $[21,22]$.

In the current study, higher pregnancy rates were determined in the control and azithromycin groups than in the LPS 


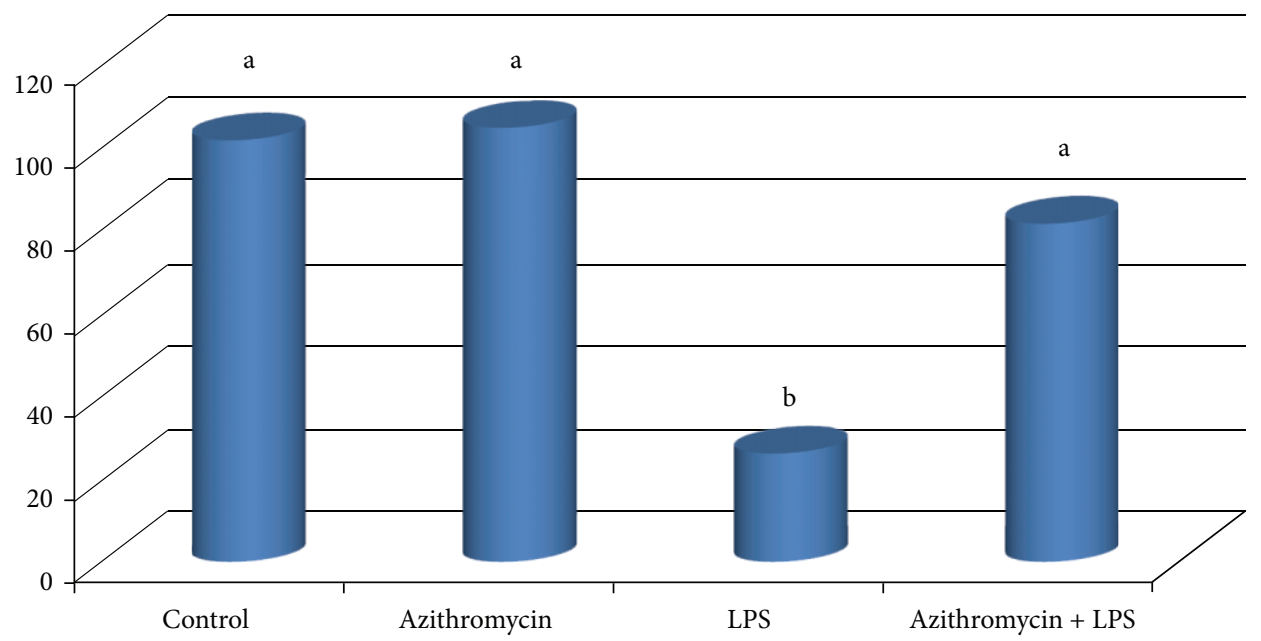

FIGURE 1: The number of offspring in groups. To induce the pregnancy loss with LPS, $160 \mu \mathrm{g} \mathrm{kg}^{-1}$ LPS (Escherichia coli 0111:B4) was administered intravenously via the tail vein on day 10 of pregnancy in LPS group. Azithromycin was administered orally at $350 \mathrm{mg} \mathrm{kg}^{-1}$ day on days 9, 10, and 11 of pregnancy in azithromycin and azithromycin + LPS groups. Blood samples were obtained from the tail vein on day 10 of the experiment and all animals were followed during pregnancy. Animals that did and did not give birth were determined. ${ }^{\mathrm{a}, \mathrm{b}}$ Different letters are statistically significant $(P<0.05)$.

group (Table 1). In addition, a higher TNF- $\alpha$ level was measured in the LPS group (Table 2). The maternal immune response is determined for pregnancy success. Animal models have been used to elucidate this question. The mechanism underlying early pregnancy loss is associated with several inflammatory molecules; thus, modulation of the inflammatory modules is useful. Excessive inflammation may lead to unfavourable outcomes, such as spontaneous abortion and fetal resorption. Areas of implantation are extremely sensitive to LPS and Th1 cytokines (TNF- $\alpha$ and IL-2) during early pregnancy in mice. These molecules have the ability to induce embryonic resorption $[3,23,24]$. Low doses of LPS, without affecting mother survival, cause high rates of embryonic resorption during early pregnancy $[3,25]$. Deregulation of cytokines networks results in adverse pregnancy outcomes [20]. Th2 cytokines, including IL-10, have a protective role, while Th1 cytokines, including TNF- $\alpha$, are abortive factors in pregnancy [26]. Increased TNF- $\alpha$ levels caused by LPS resulted in insufficient placental perfusion, improvement of thrombotic events, and placental and fetal hypoxia [27]. In the current study, the LPS treatment increased TNF- $\alpha$ level, which determined a decrease in pregnancy rate. It has been reported that the LPS-increased TNF- $\alpha$ level is closely linked to recurrent pregnancy loss [28]. In another study, the concentration of LPS-binding protein in amniotic fluid was increased in patients who had a spontaneous fetal loss [29].

In the current study, azithromycin increased the pregnancy rate 3.5-fold when compared to the LPS group (Table 1). In addition, a higher IL-10 concentration occurred $(P<0.05)$ in the azithromycin + LPS group than those of the other groups, and the TNF- $\alpha$ level was lower $(P<0.05)$ in the azithromycin + LPS group than the LPS group (Table 2). Erythromycin and azithromycin are used in the treatment of endocervical chlamydial infections and mycoplasma pneumonia in obstetric patients [30]. Azithromycin may be more effective against endometrial infections because it provides important tissue levels for a long period [31]. Transplacental passage of azithromycin is limited, and azithromycin and other macrolide antibiotics are generally accepted to be safe in pregnancy $[32,33]$. Increased pregnancy rates in the azithromycin + LPS group (Table 1) may reflect the depressive effect of macrolides on proinflammatory cytokines production and the potentiating effect on the IL-10 level. The suppressive effects of macrolides, including azithromycin, on the TNF- $\alpha$ level and the potentiating effects of these drugs on the IL-10 level have been reported [31, 34, 35]. Moreover, IL-10 injections prevent LPS-induced abortions and decrease LPS-induced fetal death $[6,27]$.

In conclusion, infection- or endotoxemia-mediated pregnancy loss may be prevented by using azithromycin during the pregnancy period.

\section{Conflict of Interests}

The author declares that there is no conflict of interests.

\section{Acknowledgments}

The author thanks Dr. Enver YAZAR and Dr. Ibrahim AYDIN for the scientific assistance.

\section{References}

[1] O. Thellin, B. Coumans, W. Zorzi, A. Igout, and E. Heinen, "Tolerance to the foeto-placental "graft": ten ways to support a child for nine months," Current Opinion in Immunology, vol. 12, no. 6, pp. 731-737, 2000.

[2] A. Friebe and P. Arck, "Causes for spontaneous abortion: what the bugs "gut" to do with it?" International Journal of Biochemistry \& Cell Biology, vol. 40, no. 11, pp. 2348-2352, 2008. 
[3] J. Aisemberg, C. Vercelli, M. Wolfson et al., "Inflammatory agents involved in septic miscarriage," NeuroImmunoModulation, vol. 17, no. 3, pp. 150-152, 2010.

[4] S. P. Murphy and S. Sharma, "IL-10 and pregnancy," in Immunology of Pregnancy, G. Mor, Ed., pp. 26-36, 2006.

[5] D.-X. Xu, Y.-H. Chen, H. Wang, L. Zhao, J.-P. Wang, and W. Wei, "Tumor necrosis factor alpha partially contributes to lipopolysaccharide-induced intra-uterine fetal growth restriction and skeletal development retardation in mice," Toxicology Letters, vol. 163, no. 1, pp. 20-29, 2006.

[6] S. A. Robertson, A. S. Care, and R. J. Skinner, "Interleukin 10 regulates inflammatory cytokine synthesis to protect against lipopolysaccharide-induced abortion and fetal growth restriction in mice," Biology of Reproduction, vol. 76, no. 5, pp. 738-748, 2007.

[7] C. Holmgren, M. S. Esplin, S. Hamblin, M. Molenda, S. Simonsen, and R. Silver, "Evaluation of the use of anti-TNF$\alpha$ in an LPS-induced murine model," Journal of Reproductive Immunology, vol. 78, no. 2, pp. 134-139, 2008.

[8] M. Cella, M. G. Farina, A. P. Dominguez Rubio, G. Di Girolamo, M. L. Ribeiro, and A. M. Franchi, "Dual effect of nitric oxide on uterine prostaglandin synthesis in a murine model of preterm labour," British Journal of Pharmacology, vol. 161, no. 4, pp. 844$855,2010$.

[9] F. Tuzun, A. Kumral, M. Dilek et al., "Maternal omega-3 fatty acid supplementation protects against lipopolysaccharideinduced white matter injury in the neonatal rat brain," The Journal of Maternal-Fetal and Neonatal Medicine, vol. 25, no. 6, pp. 849-854, 2012.

[10] O. B. Christiansen, H. S. Nielsen, and A. M. Kolte, "Inflammation and miscarriage," Seminars in Fetal and Neonatal Medicine, vol. 11, no. 5, pp. 302-308, 2006.

[11] J. Trowsdale and A. G. Betz, "Mother's little helpers: mechanisms of maternal-fetal tolerance," Nature Immunology, vol. 7, no. 3, pp. 241-246, 2006.

[12] A. Er and E. Yazar, "Effects of tylosin, tilmicosin and tulathromycin on inflammatory mediators in bronchoalveolar lavage fluid of lipopolysaccharide-induced lung injury," Acta Veterinaria Hungarica, vol. 60, pp. 465-476, 2012.

[13] E. Pitsouni, C. Iavazzo, S. Athanasiou, and M. E. Falagas, "Single-dose azithromycin versus erythromycin or amoxicillin for Chlamydia trachomatis infection during pregnancy: a metaanalysis of randomised controlled trials," International Journal of Antimicrobial Agents, vol. 30, no. 3, pp. 213-221, 2007.

[14] A. A. Adimora, "Treatment of uncomplicated genital Chlamydia trachomatis infections in adults," Clinical Infectious Diseases, vol. 35, no. 2, pp. S183-S186, 2002.

[15] G. W. Amsden, "Erythromycin, clarithromycin, and azithromycin: are the differences real?" Clinical Therapeutics, vol. 18, no. 1 , pp. 56-72, 1996.

[16] H. Rothberg, "Effects of cytotoxic agents on the fetus," JAMA, vol. 173, no. 14, p. 1616, 1960.

[17] K. M. Fetalvero, P. Zhang, M. Shyu et al., "Prostacyclin primes pregnant human myometrium for an enhanced contractile response in parturition," Journal of Clinical Investigation, vol. 118, no. 12, pp. 3966-3979, 2008.

[18] E. Jauniaux, R. G. Farquharson, O. B. Christiansen, and N. Exalto, "Evidence-based guidelines for the investigation and medical treatment of recurrent miscarriage," Human Reproduction, vol. 21, no. 9, pp. 2216-2222, 2006.
[19] F. Zegers-Hochschild, G. D. Adamson, J. De Mouzon et al., "The International Committee for Monitoring Assisted Reproductive Technology (ICMART) and the World Health Organization (WHO) Revised Glossary on ART Terminology, 2009," Human Reproduction, vol. 24, no. 11, pp. 2683-2687, 2009.

[20] J. R. Challis, C. J. Lockwood, L. Myatt, J. E. Norman, J. F. Strauss III, and F. Petraglia, "Inflammation and pregnancy," Reproductive Sciences, vol. 16, no. 2, pp. 206-215, 2009.

[21] L. V. Wilton, G. L. Pearce, R. M. Martin, F. J. Mackay, and R. D. Mann, "The outcomes of pregnancy in women exposed to newly marketed drugs in general practice in England," British Journal of Obstetrics and Gynaecology, vol. 105, no. 8, pp. 882-889, 1998.

[22] C. Giorlandino, P. Cignini, M. Cini et al., "Antibiotic prophylaxis before second-trimester genetic amniocentesis (APGA): a single-centre open randomised controlled trial," Prenatal Diagnosis, vol. 29, no. 6, pp. 606-612, 2009.

[23] S. M. Laird, E. M. Tuckerman, B. A. Cork, S. Linjawi, A. I. F. Blakemore, and T. C. Li, "A review of immune cells and molecules in women with recurrent miscarriage," Human Reproduction Update, vol. 9, no. 2, pp. 163-174, 2003.

[24] B. F. Mitchell and M. J. Taggart, "Are animal models relevant to key aspects of human parturition?" American Journal of Physiology, vol. 297, no. 3, pp. R525-R545, 2009.

[25] L. Li, J. Yang, L. Ren, N. Su, Y. Fang, and Y. Lin, "Invariant NKT cells increase lipopolysacchride-induced pregnancy loss by a mechanism involving Thl and Th17 responses," Journal of Maternal-Fetal and Neonatal Medicine, vol. 26, pp. 1212-1218, 2013.

[26] G. Chaouat, S. Zourbas, S. Ostojic et al., "A brief review of recent data on some cytokine expressions at the maternofoetal interface which might challenge the classical Th1/Th2 dichotomy," Journal of Reproductive Immunology, vol. 53, no. 12, pp. 241-256, 2002.

[27] S. J. Renaud, T. Cotechini, J. S. Quirt, S. K. MacdonaldGoodfellow, M. Othman, and C. H. Graham, "Spontaneous pregnancy loss mediated by abnormal maternal inflammation in rats is linked to deficient uteroplacental perfusion," Journal of Immunology, vol. 186, no. 3, pp. 1799-1808, 2011.

[28] R. L. Gendron, F. P. Nestel, W. S. Lapp, and M. G. Baines, "Lipopolysaccharide-induced fetal resorption in mice is associated with the intrauterine production of tumour necrosis factoralpha," Journal of Reproduction and Fertility, vol. 90, no. 2, pp. 395-402, 1990.

[29] J. Espinoza, R. Romero, T. Chaiworapongsa et al., "Lipopolysaccharide-binding protein in microbial invasion of the amniotic cavity and human parturition," Journal of Maternal-Fetal and Neonatal Medicine, vol. 12, no. 5, pp. 313-321, 2002.

[30] P. Duff, "Antibiotic selection in obstetric patients," Infectious Disease Clinics of North America, vol. 11, no. 1, pp. 1-12, 1997.

[31] R. H. Gray, F. Wabwire-Mangen, G. Kigozi et al., "Randomized trial of presumptive sexually transmitted disease therapy during pregnancy in Rakai, Uganda," American Journal of Obstetrics and Gynecology, vol. 185, no. 5, pp. 1209-1217, 2001.

[32] T. Heikkinen, K. Laine, P. J. Neuvonen, and U. Ekblad, "The transplacental transfer of the macrolide antibiotics erythromycin, roxithromycin and azithromycin," British Journal of Obstetrics and Gynaecology, vol. 107, no. 6, pp. 770-775, 2000.

[33] M. Sarkar, C. Woodland, G. Koren, and A. R. N. Einarson, "Pregnancy outcome following gestational exposure to azithromycin," BMC Pregnancy and Childbirth, vol. 6, article 18, 2006. 
[34] S.-J. Lin, D.-C. Yan, W.-I. Lee, M.-L. Kuo, H.-S. Hsiao, and P.Y. Lee, "Effect of azithromycin on natural killer cell function," International Immunopharmacology, vol. 13, no. 1, pp. 8-14, 2012.

[35] M. Vrančić, M. Banjanac, K. Nujić et al., "Azithromycin distinctively modulates classical activation of human monocytes in vitro," British Journal of Pharmacology, vol. 165, no. 5, pp. 13481360, 2012. 


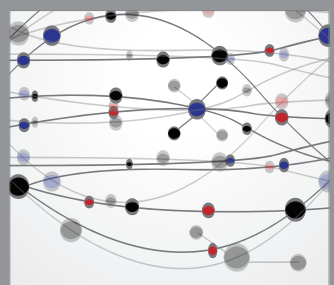

The Scientific World Journal
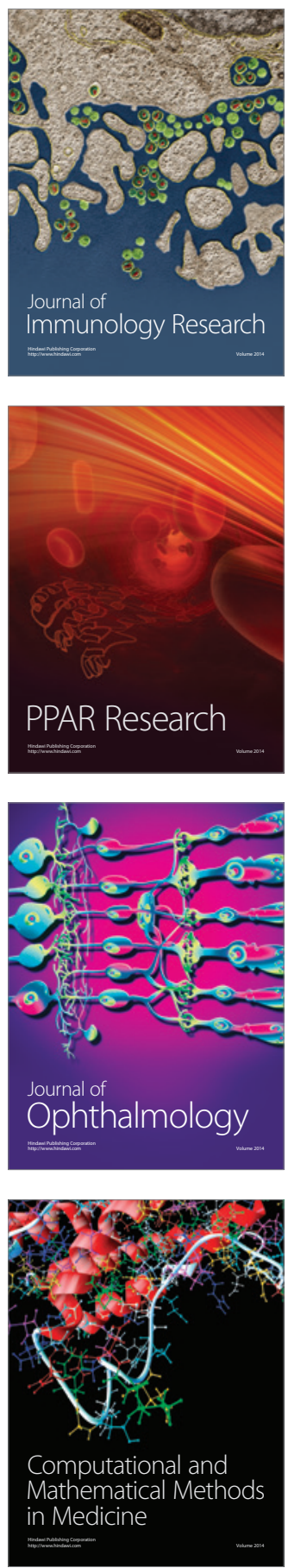

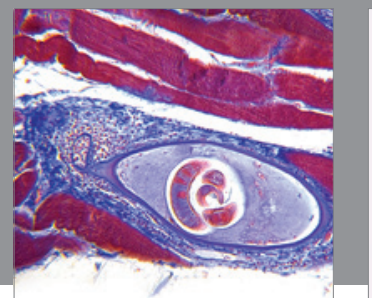

Gastroenterology

Research and Practice
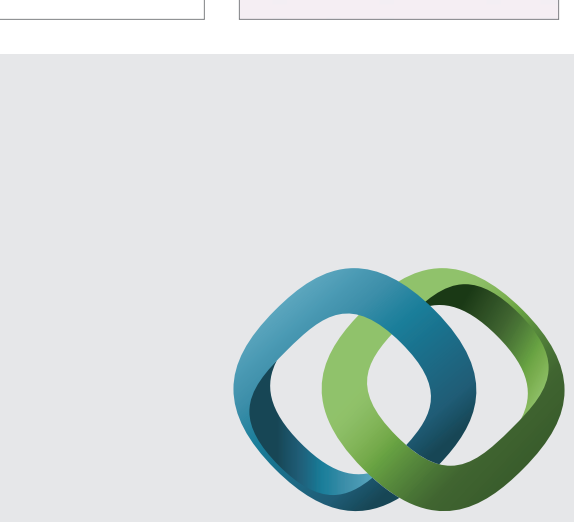

\section{Hindawi}

Submit your manuscripts at

http://www.hindawi.com
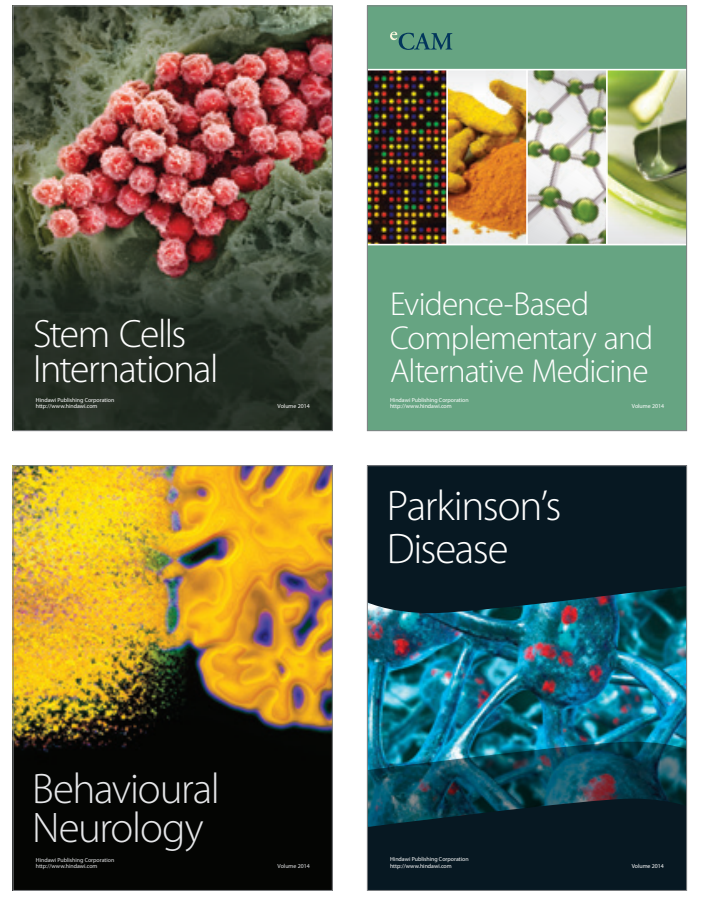
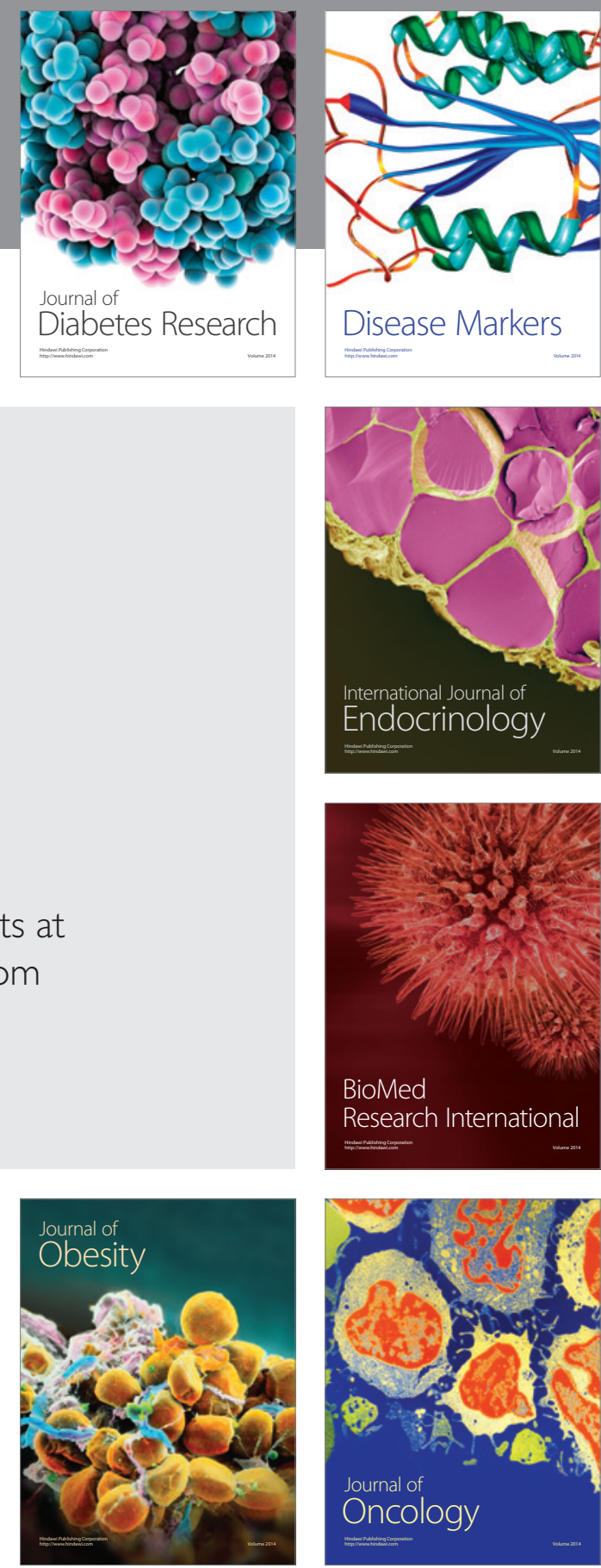

Disease Markers
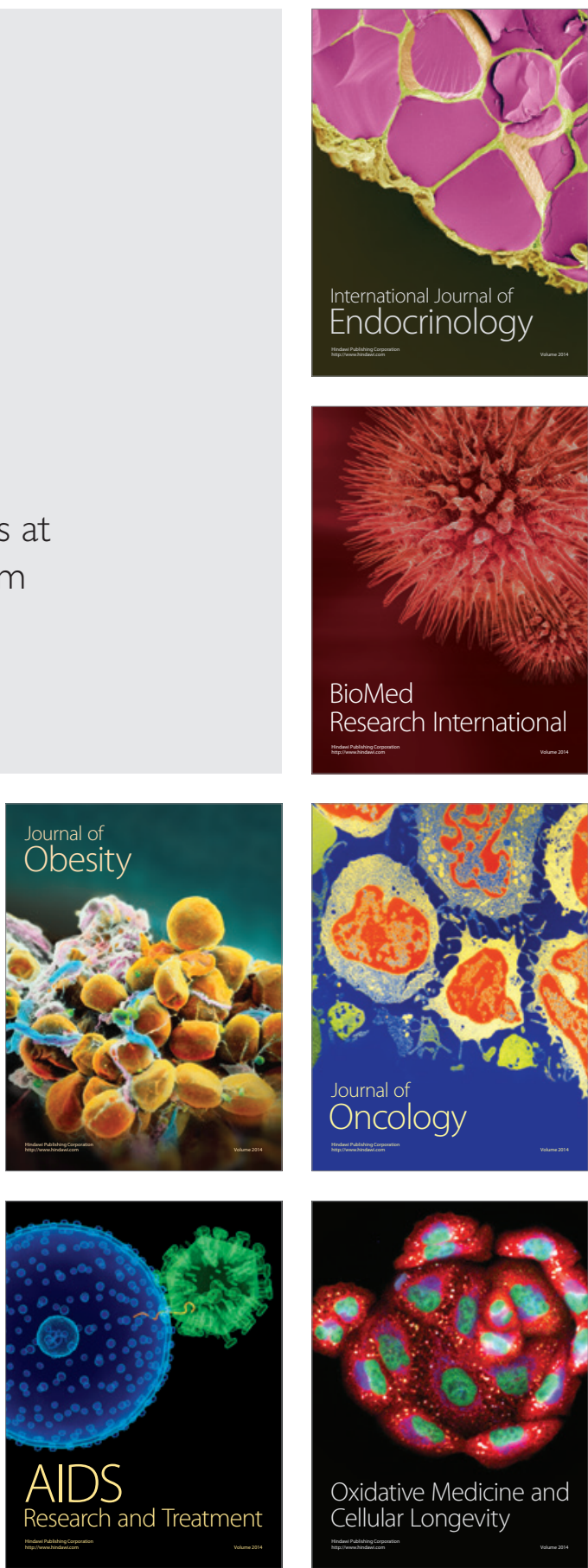